\title{
Editorials
}

\section{Co-opting psychiatry: The alliance between academic psychiatry and the pharmaceutical industry}

\author{
JOANNA MONCRIEFF
}

\begin{abstract}
The Editorial present the arguments that an alliance between academic psychiatry and the pharmaceutical industry is harmful through a critical review of the academic literature and media coverage of activities of the pharmaceutical industry. The industry and the psychiatric profession both gain advantages from promoting biomedical models of psychiatric disturbance and pharmacological treatment. This confluence of interests has lead to the exaggeration of the efficacy of psychiatric drugs and neglect of their adverse effects and has distorted psychiatric knowledge and practice. Academic psychiatry has helped the industry to colonise more and more areas of modern life in order to expand the market for psychotropic drugs. Persuading people to understand their problems as biological deficiencies obscures the social origin and context of distress and prevents people from seeking social or political solutions. Psychiatry has the power to challenge the dominance of the pharmaceutical industry and should put its efforts into developing alternatives to routine drug treatment. Psychiatry needs to disengage from the industry if it wants to make genuine advances in understanding psychiatric disorder and help reverse the harmful social consequences of the widening medicalisation of human experience.
\end{abstract}

The influential alliance between psychiatry and the pharmaceutical industry dates back to the introduction of the first modern psychotropic drugs in the 1950s and 60s. These drugs fulfilled psychiatry's desire to have specific physical therapies at its disposal and presented new marketing opportunities for the growing industry.

There has long been an inclination within psychiatry to emphasise the role of biological factors in the aetiology and treatment of mental disorders. In the $19^{\text {th }}$ century a biological orientation helped the emergent profession to establish its authority over the asylums and (Jacyna, 1982 ) in the early $20^{\text {th }}$ century it was a key part of the profession's efforts to improve its reputation, status, pay and the condition of its patients by aligning itself closer to general medicine, (Moncrieff \& Crawford, 2001; Scull, $1994)$. In the early $20^{\text {th }}$ century physical procedures were

Address for correspondence: Professor Dr. J. Moncrieff, Department of Mental Health Sciences, University College London, Gower Street, London WC1E 6BT (United Kingdom).

Fax: ++44-1277-302696

E-mail: j.moncrieff@ucl.ac.uk

Declaration of Interest: I am the co-chair person of the Critical Psychiatry Network, an international network of psychiatrists who are critical of the dominance of biomedical models of psychiatric distress. I have no financial interests that would be affected by publication of this paper. popular including insulin coma therapy, lobotomy and electro shock therapy because they appeared to suggest that intervening on the body could cure the troubles of the mind. In the 1950s and 1960s the role of the physical treatments passed to the new drugs, which were greeted with great enthusiasm and soon credited with acting on the neuropathological basis of specific disorders (Moncrieff, 1999).

The pharmaceutical industry was closely involved in the development and dissemination of the new range of psychiatric drugs from the 1950s. Chlorpromazine was introduced to the United States for example in a huge marketing campaign mounted by SmithKline that included television appearances by the managing director and lobbying of local politicians and health service funders (Swazey, 1974). These activities helped to strengthen the biomedical hegemony within psychiatry. "Without industry" psychopharmacologist Tom Ban suggested "the medicalisation of psychiatry would be far from where it is today and neither the diagnosis nor the treatment of mental illness would be sufficiently advanced that psychiatry could participate in an integrated healthcare system with other branches of medicine" (Ban, 1996) (P 593).

Ban, like much of the psychiatric profession, believes that the alliance between psychiatry and the pharmaceutical industry has benefited patients and society by improving the treatment of mental illness. In contrast critics suggest that the widespread use of modern psychiatric 
drugs results in more harm than good (Breggin, 1993). Psychiatry with its medical credentials and associated respectability, and the financial power of the industry represents a formidable combination. In the rest of this paper I suggest that rather than advancing our understanding of the actions of psychiatric drugs and the interests of patients, the vested interests of these two groups have distorted the evidence, consistently overestimating the benefits of psychiatric drugs and obscuring their adverse effects. At a social level this powerful alliance of interests has persuaded an increasing proportion of people to identify their problems as illnesses that require drug treatment, helping to create a society that expects a quick fix for all its troubles and blinds itself to its own failings (Hamilton, 2003).

\section{DISTORTING THE EVIDENCE-EXAGGERATING BENEFITS}

The pharmaceutical industry conducts the majority of clinical drug trials on which decisions about the efficacy and safety of drugs are based. Even where these trials are conducted in collaboration with academic centres, the sponsoring company usually owns and controls the data and only allows access to selected parts of it, if any. There is good evidence that companies often chose not to publish trials that have negative results, and within published reports positive outcomes are accentuated and negatives ones omitted or buried (Melander et al., 2003; Whittington et al., 2004).

Some commentators have suggested that the design of placebo controlled randomised trials is likely to exaggerate the effects of the active drug relative to placebo due to unblinding and the possibility of differential dropout (Kaptchuk, 2001). In addition, in comparative trials use of comparator drugs with high levels of adverse effects may exaggerate the benefits of newer drugs. In long-term trials withdrawal related morbidity in the placebo group may confound results (Moncrieff, 2006). Categorising continuous data may also lead to inflated estimates of efficacy (Kirsch \& Moncrieff, 2007).

Data from clinical trials can therefore easily be made to fit the agenda of the authors or the sponsors or moulded to suit broader social interests. A recent analysis, for example, demonstrated that results of comparative trials favoured the sponsors drug in $90 \%$ of cases, leading to mutually contradictory results (Heres et al., 2006). This situation has lead at best to the overuse of psychiatric drugs, and at worst to the use of drugs in situations where they are completely useless and potentially harmful. For example, antidepressants are thought to be beneficial in depression, even though they are only marginally better than placebo and no research has demonstrated that they have a specifically "antidepressant" effect (Moncrieff \& Cohen, 2006). Long-term treatment with neuroleptics and "mood stabilizers" is widely recommended with little regard for the fact that withdrawal related problems undermine the basis of the evidence. The use of new and more expensive drugs has been promoted over older ones.

\section{ADVERSE EFFECTS}

The "atypical" antipsychotic drugs olanzapine and clozapine are known to be associated with substantial weight gain, which is associated with increased risk of diabetes, dyslipidaemia and heart disease (Newcomer \& Haupt, 2006). In 2006, a New York Times article, based on previously confidential internal documents, alleged that the drug company Eli Lilly "has engaged in a decade long effort to play down the health risks of Zyprexa (olanzapine)" (Alex Berenson, 2006). Lilly denies the accusations but the company has already made an out of court settlement to 8000 people claiming drug induced diabetes. Lilly has also been promoting the idea that diabetes is inherently linked with severe mental illness, even suggesting a possible common genetic link. Academic psychiatrists have been involved in this endeavour, authoring papers in a Lilly sponsored supplement of the British Journal of Psychiatry, for example, which extensively discuss the links between schizophrenia and diabetes and make scant mention of drug related effects (Dinan, 2004).

Internal documents from GlaxoSmithKline revealed by $A B C$ news in the United States suggested the company attempted to minimize the risk and impact of withdrawal symptoms associated with their antidepressant drug Paxil (paroxetine) (Fisher et al., 2004). More recently documents obtained by the BBC programme Panorama revealed the way in which the results of an essentially negative trial of paroxetine in children were presented in a way that masked the lack of efficacy and played down adverse effects including suicidal behaviour in what Joe Collier described in the British Medical Journal as a "conspiracy orchestrated by the drug company" (Collier, 2007) (P 209).

But drug companies are not soley responsible for the neglect of the adverse effects of drug treatments. Academic psychiatry has paid little attention to some of the most serious complications of treatment. For example, although it is widely recognized that long-term use of neuroleptics induces a neurological disorder consisting of 
abnormal movements, known as Tardive Dyskinesia, suggestive evidence that it is associated with cognitive impairment and may be a manifestation of global drug induced brain damage has not received the attention it deserves (Waddington \& Youssef, 1996). In addition the academic community has spent years investigating structural features of the brains of people with schizophrenia and paid little attention to the effects of drug treatment. In 2005 , results of the largest ever study of the brains of people with first episode psychosis was published. The study was a collaboration between Eli Lilly scientists and leading psychiatric academics and the results were reported as showing that haloperidol treatment was associated with a detectable reduction in brain grey matter after 12 weeks treatment. No effects of olanzapine were mentioned but data presented in the Tables reveals that olanzapine was also associated with grey matter reductions after one year of treatment, albeit less pronounced than those associated with haloperidol (Lieberman et al., 2005). A smaller study showed reduced brain matter in patients treated with first generation neuroleptics compared with non drug treated patients over a nine week period (Dazzan et al., 2005). Despite these studies, literature on progressive changes in brain structure in people with psychosis barely mentions the confounding effects of drug treatment and the above studies are not cited in subsequent reviews (Steen et al., 2006).

\section{MARKETING MENTAL ILLNESS}

The pharmaceutical industry has an obvious interest in increasing the size of its market. A pharmaceutical industry trade publication guide to "medical education" was quite explicit about the need to "create dissatisfaction in the market", "establish a need" and "create a desire" (Pharmaceutical Marketing, 2000). However, the fact that the industry has successfully co-opted the psychiatric profession to this aim has helped to provide a respectable and apparently objective cloak for its expansive ambitions.

The Defeat Depression Campaign was conducted in the United Kingdom under the auspices of the Royal College of Psychiatrists and the Royal College of General Practitioners in the early 1990s. It was part funded by Eli Lilly, the makers of Prozac. Its message was that depression was more common than previously thought, and that it should be diagnosed and treated more often. The literature suggested that $5 \%$ of the general population suffer from depression at any given time, that $20 \%$ of GP attenders have symptoms of depression and that around half of these require treatment (Paykel \& Priest, 1992). As a con- sequence of this campaign, as well as general marketing, prescriptions for antidepressants in the UK increased by $243 \%$ in the 10 years up to 2002 (National Institute for Clinical Excellence, 2004). Levels of antidepressant prescribing are now so high that guidelines are calling for them to be reduced (National Institute for Clinical Excellence, 2004).

The industry has also been involved in expanding the boundaries of psychosis and schizophrenia by popularizing notions of early intervention and preventive treatment of psychosis. Companies that make second generation neuroleptic drugs have sponsored conferences and journal supplements on Early Intervention and funded two drug trials involving the treatment of young people considered to be at "high risk" of psychosis. Despite little direct evidence that early intervention or preventive treatment is beneficial and little consideration of the harmful consequences of treating people who might never develop full blown psychosis or enduring mental illness with long-term drug treatment, use of neuroleptic drugs in young people is increasing (Olfson et al., 2006) and the threshold for prescribing these potentially damaging drugs is being pushed down.

As well as extending the boundaries of previously recognized conditions the pharmaceutical industry has sought to establish new conditions, and they have again been helped in this effort by sections of academic psychiatry. Research into the new DSM IV condition of "Intermittent Explosive Disorder," an obviously expandable category involving outbursts of temper, was conducted at Harvard University, funded by a number of drug companies (Kessler et al., 2006). Research into "Compulsive shopping disorder" has been carried out at Stanford University psychiatric department and elsewhere funded by manufacturers of serotonin re-uptake inhibitors (Koran et al., 2003). These alliances utilize the authority of academic psychiatry to establish new markets for the industry.

Teen screen, a screening instrument for school children, was developed at Columbia University by academic psychiatrists without industry funding and its use is being advocated to "uncover the epidemic of mental illness among teenagers" (Friedman, 2006). It is being introduced into American schools where it has been found to identify a third to a half of children tested as being in need of treatment (Friedman, 2006; Moore, 2007). Although the treatment recommended need not involve the prescription of drugs, it is likely that drugs will be recommended in some cases, thereby increasing further the already increasing prescription of psychotropic drugs to children. 


\section{SETTING THE AGENDA}

The preceding discussion supports David Healy's suggestion that the influence of the pharmaceutical industry is so pervasive that it now effectively sets the scientific agenda within psychiatry (Healy, 2006). Even where there is no undue direct influence, academic outputs and guidelines reflect the interests of industry and represent the evidence accordingly. Thus although the influential Texas Medication Alorgorithm Project was directly funded by manufacturers of atypical neuroleptics, consensus conferences of academic psychiatrists and United Kingdom government guidelines came to the same conclusions with relatively limited input from industry. They recommended the use of second generation neuroleptic drugs over older agents, despite the fact that there has been no convincing demonstration of their superiority and their costs are considerably higher (Healy, 2006). Publications that suggest a much higher incidence of manic depression or bipolar disorder than previously thought co-incide with the marketing of sodium valproate and other new "mood stabilizers" but have been authored by respected academic psychiatrists whose research was not funded by drug companies (Angst et al., 2003). The idea of a "psychosis-spectrum" has been discussed by leading academics (Craddock \& Owen, 2005), who were angered at the suggestion that they were influenced by their connections with the pharmaceutical industry (Editor, 2005). But the point is not whether or not individuals are influenced. It is the fact that the ubiquitous influence of industry is able to create a climate in which ideas that favour its interests flourish and countervailing evidence can be ignored.

\section{POLITICAL CONSEQUENCES}

In $200211 \%$ of women and $5 \%$ of men in the United States were prescribed antidepressants (Stagnitti, 2005). People in western society have been successfully persuaded to "recode their ills in terms of their brain chemicals" (Rose, 2004) (P28) and to view drugs as the appropriate solution. The idea that we should all aspire to some hypothetical state of ideal mental or chemical "balance" and take drugs to achieve it is consistent with the ideals of a consumerist society that needs to encourage dissatisfaction in order to maintain consumption. In the same way that the ubiquitous advertising of goods encourages people to be dissatisfied with what they have, the marketing of psychiatric conditions and treatments encourages people to be dissatisfied with themselves. Just as buying goods only fuels the desire for more, the use of drugs can merely confirm the inadequacy of one's biochemistry. Undermining people's confidence in this way makes them more vulnerable and less able to challenge social forces that act against their interests. Thus detrimental social changes such as rising levels of unemployment, increased hours and intensity of work, lower pay and increased insecurity of employment are challenged less effectively than they might otherwise be. And because concern has become successfully focused on brain chemistry, the social or interpersonal nature of most human difficulties is obscured. The ways in which the competitiveness and inequality of modern society breed discontent in the first place can be ignored and social and political solutions discounted. As psychiatrist Bradley Lewis put it: "If we plug human suffering, misery and sadness into the calculus of bioscience, there is no need to make changes in the social order, instead, we only need to jumpstart some neurotransmitters" (Lewis, 2003) (P 56).

\section{NEGLECTING ALTERNATIVES}

Unlike the pharmaceutical industry which is motivated simply to sell drugs, the psychiatric profession has always included many perspectives on the nature and treatment of mental disorder, as well as the traditional biomedical approach. Psychoanalysis, psychotherapy, social psychiatry and more recently the "recovery model" all offer explanations and treatment approaches that emphasise the role of development and social environment in the origin and meaning of an individual's problems. Psychotherapy and other non drug based treatments are widely accepted for milder conditions and personality disorders and a few projects have attempted to investigate alternatives to routine drug treatment for people with psychosis. A recent study, for example, found that $43 \%$ of people with a first episode could be successfully treated without neuroleptic drugs (Lehtinen et al., 2000).

The alliance between psychiatry and the pharmaceutical industry is mutually re-inforcing. The drugs developed and promoted by industry lend scientific credibility to psychiatry, which lends professional credibility to the profit driven activities of the industry. The influence of this powerful alliance has produced a body of knowledge and conventional practice that shapes reality in its own interests. Although psychiatry has its own motives for promoting drug treatment, the profession also has the potential to challenge the influence of the pharmaceutical industry alongside other parts of the medical profession. To do this psychiatry needs to disentangle itself from its

Epidemiologia e Psichiatria Sociale, 16, 3, 2007 
relationship with the pharmaceutical industry. The acceptance of gifts from free pens to trips abroad must be discouraged and academics should not be allowed to own shares or benefit financially from company's whose products they are investigating. Journals should refuse to publish ghost written articles and studies where the raw data is not freely available. Only when psychiatry is truly independent can it contribute to a better understanding of psychiatric suffering and help to combat the insidious medicalisation of human problems.

\section{REFERENCES}

Alex Berenson (2006). Eli Lilly said to play down risk of top pill. New York Times, 17 December 2006.

Angst J., Gamma A., Benazzi F., Ajdacic V., Eich \& Rossler W. (2003). Toward a re-definition of subthreshold bipolarity: epidemiology and proposed criteria for bipolar-II, minor bipolar disorders and hypomania. Journal of Affective Disorders 73, 133-146.

BanT. (1996). They used to call it psychiatry. In The Psychopharmacologists, Vol. 1 (ed. D. Healy), pp. 587-620. Altman (Chapman and Hall): London.

Breggin P.R. (1993). Toxic Psychiatry. Fontana: London.

Collier J. (2007). Inside big pharma's box of tricks. British Medical Journal 334, 209.

Craddock N. \& Owen M.J. (2005). The beginning of the end for the Kraeplinian dichotomy. British Journal of Psychiatry 186, 364-366.

Dazzan P., Morgan K.D., Orr K., Hutchinson G., Chitnis X., Suckling J., Fearon P., McGuire P.K., Mallett R.M., Jones P.B., Leff J. \& Murray R.M. (2005). Different effects of typical and atypical antipsychotics on grey matter in first episode psychosis: the AESOP study. Neuropsychopharmacology 30, 765-774.

Dinan T.G. (2004). Schizophrenia and diabetes 2003: An expert consensus meeting. British Journal of Psychiatry, Suppl. Apr., 47, s53554.

Editor (2005). Corrigendum for Calton, British J Psych 187(2) 195. British Joumal of Psychiatry 187, 390.

Fisher G., Sheeky K., Launier K. \& Lallanilla M. (2004). Drug maker withheld Paxil study data. $A B C$ News, 9 December 2004.

Friedman R.A. (2006). Uncovering an epidemic--screening for mental illness in teens. New England Journal of Medicine 355, 2717-2719.

Hamilton C. (2003). Growth Fetish. Allen \& Unwin: Sydney.

Healy D. (2006). Manufacturing consensus. Culture Medicine and Psychiatry 30, 135-156.

Heres S., Davis J., Maino K., Jetzinger E., Kissling W. \& Leucht S. (2006). Why olanzapine beats risperidone, risperidone beats quetiapine, and quetiapine beats olanzapine: an exploratory analysis of head-to-head comparison studies of second-generation antipsychotics. American Journal of Psychiatry 163, 185-194.

Jacyna L.S. (1982). Somatic theories of mind and the interests of medicine in Britain 1850-1879. Medical History 16, 233-258.

Kaptchuk T.J. (2001). The double-blind, randomized, placebo-controlled trial: gold standard or golden calf? Journal of Clinical Epidemiology 54, 541-549.

Kessler R.C., Coccaro E.F., Fava M., Jaeger S., Jin R. \& Walters E. (2006). The prevalence and correlates of DSM-IV intermittent explosive disorder in the National Comorbidity Survey Replication. Archives of General Psychiatry 63, 669-678.

Kirsch I. \& Moncrieff J. (2007). Clinical trials and the response rate illusion. Contemporary Clinical Trials 28(4), 348-351.

Koran L.M., Chuong H.W., Bullock K.D. \& Smith S.C. (2003). Citalopram for compulsive shopping disorder: an open-label study followed by double-blind discontinuation. Journal of Clinical Psychiatry 64, 793-798.

Lehtinen V., Aaltonen J., Koffert T., Rakkolainen V. \& Syvalahti E. (2000). Two-year outcome in first-episode psychosis treated according to an integrated model. Is immediate neuroleptisation always needed? European Psychiatry 15, 312-320.

Lewis B.E. (2003). Prozac and the post-human politics of cyborgs. Journal of Medical Humanities 24, 49-63.

Lieberman J.A., Tollefson G.D., Charles C., Zipursky R., Sharma T., Kahn R.S., Keefe R.S., Green A.I., Gur R.E., McEvoy J., Perkins D., Hamer R.M., Gu H., Tohen M. \& HGDH Study Group (2005). Antipsychotic drug effects on brain morphology in first-episode psychosis. Archives of General Psychiatry 62, 361-370.

Melander H., Ahlqvist-Rastad J., Meijer G. \& Beermann B. (2003). Evidence b(i)ased medicine--selective reporting from studies sponsored by pharmaceutical industry: review of studies in new drug applications. British Medical Journal 326, 1171-1173.

Moncrieff J. (1999). An investigation into the precedents of modern drug treatment in psychiatry. History of Psychiatry 10, 475-490.

Moncrieff J. (2006). Why is it so difficult to stop psychiatric drug treatment? It may be nothing to do with the original problem. Medical Hypotheses 67, 517-523.

Moncrieff J. \& Cohen D. (2006). Do antidepressants cure or create abnormal brain states? PLoS Medicine 3, e240.

Moncrieff J. \& Crawford M.J. (2001). British psychiatry in the 20th century--observations from a psychiatric journal. Social Science and Medicine 53, 349-356.

Moore S. (2007). First time mental-health screening identifies need. The Press Republican, 28 January 2007.

National Institute for Clinical Excellence (2004). Depression: Management of Depression in Primary and Secondary Care. Clinical Practice Guideline Number 23. National Institute for Clinical Excellence: London.

Newcomer J.W. \& Haupt D.W. (2006). The metabolic effects of antipsychotic medications. Canadian Journal of Psychiatry 51, 480-491.

Olfson M., Blanco C., Liu L., Moreno C. \& Laje G. (2006). National trends in the outpatient treatment of children and adolescents with antipsychotic drugs. Archives of General Psychiatry 63, 679-685.

Paykel E.S. \& Priest R.G. (1992). Recognition and management of depression in general practice: consensus statement. British Medical Journal 305, 1198-1202.

Pharmaceutical Marketing (2000). Practical Guides: Medical Education, Parts I and II. Pharmaceutical Marketing. Retrieved June 4, 2007, from http://www.pmlive.com

Rose N. (2004). Becoming neurochemical selves. In Biotechnology, Commerce and Civil Society (ed. N. Stehr), pp. 89-128. Transaction Publishers: New Brunswick (N.J.).

Scull A. (1994). Somatic treatments and the historiography of psychiatry. History of Psychiatry 5(17 Pt.1), 1-12.

Stagnitti M. (2005). Antidepressant Use in the US Civilian NonInstitutionalised Population, 2002. Statistical Brief \#77. Medical Expenditure Panel, Agency for Healthcare Research and Quality: Rockville,MD.

Steen R.G., Mull C., McClure R., Hamer R.M. \& Lieberman J.A. (2006). Brain volume in first-episode schizophrenia: systematic review and meta-analysis of magnetic resonance imaging studies. British Journal of Psychiatry 188, 510-518.

Swazey J. (1974). Chlorpromazine in Psychiatry. Massachusetts Institute of Technology: Cambridge, MA.

Waddington J.L. \& Youssef H.A. (1996). Cognitive dysfunction in chronic schizophrenia followed prospectively over 10 years and its longitudinal relationship to the emergence of tardive dyskinesia. Psychological Medicine 26, 681-688.

Whittington C.J., Kendall T., Fonagy P., Cottrell D., Cotgrove A. \& Boddington E. (2004). Selective serotonin reuptake inhibitors in childhood depression: systematic review of published versus unpublished data. Lancet 363, 1341-1345. 